\title{
Compulsion in the community? The introduction of supervised community treatment ${ }^{\dagger}$
}

\author{
Guy Brookes \& Nick Brindle
}

\begin{abstract}
SUMMARY
Supervised community treatment (SCT) is one of the most prominent amendments to the Mental Health Act 1983. It has divided opinion among health professionals and introduces significant powers not previously available in England and Wales. This article considers how SCT fits into the established legislative framework and how it may affect the care delivered by mental health practitioners.
\end{abstract}

\section{DECLARATION OF INTEREST}

None.

For most mental health practitioners working in England and Wales, the Mental Health Act 1983 is considered to apply to patients in hospital. People may be detained and treated against their wishes when clinicians judge that risks cannot be managed in the community. The 2007 amendments to the Act support treatment outside hospital and allow forced recall to hospital for patients subject to supervised community treatment (SCT) by virtue of a community treatment order (CTO) (Section 17A). Ethical and practical concerns have been raised by professional and patient groups (Mental Health Alliance 2006) who have not wholly welcomed the addition, but the stated aim is to prevent repeated relapse in a vulnerable group of patients well-known to services and thus improve their quality of life.

In this article we will consider the circumstances in which patients may be subject to SCT. We will also consider:

- conditions that may be applied to SCT

- treatment that may be given under its authority

- how SCT may be used to manage relapse.

The power to treat and set conditions for patients subject to SCT allows the clinician to maintain some control over the actions of an individual while they are residing in the community. Use of SCT should be considered alongside other needs and as part of a comprehensive care plan. Clinicians must be satisfied that powers are required and that the aims cannot be achieved on a voluntary and collaborative basis. If compulsion is required, the guiding principles of the Mental Health Act should always be borne in mind (Box 1).

Before the introduction of SCT in the 2007 amendments there were three different mechanisms available to supervise unrestricted patients: leave of absence under Section 17, guardianship and supervised discharge (repealed by the 2007 amendments). It is sensible to discuss the available alternatives prior to any discussion of SCT. A summary of guidance on the use of SCT, guardianship and Section 17 leave is given in Box 2.

\section{Section 17 leave of absence}

From a legislative perspective, SCT represents an amendment of Section 17 and it is helpful to consider this in the context of Section 17 provisions. Section 17 Leave of Absence allows the patient to leave the hospital for specified periods. Conditions may be attached by the responsible clinician for therapeutic and risk management purposes. Section 17 leave can only be granted by the responsible clinician (Box 3), although it should be part of a broader multiprofessional care plan. The use of Section 17 leave allows the patient to receive specific treatments off site, to participate in home-based rehabilitation and to maintain a social network.

BOX 1 Guiding principles of the Mental Health Act 1983 Code of Practice

The following principles are designed to guide decisions made using the Mental Health Act.

1 Purpose principle - minimising undesirable effects of mental disorder and maximising safety and well-being while promoting recovery and protecting others

2 Least restriction principle

3 Respect principle - with regard to background and wishes

4 Participation principle - involving patients, family and carers as much as possible in planning and decision-making

5 Effectiveness, efficiency and equity principle - with regard to use of resources Although all of the above principles are important, it is clear that the primary principle is the purpose principle and all others should be considered in light of it.

(Department of Health 2008a) 
B0X 2 Circumstances for the use of community powers
Section 17 leave of absence

Allows temporary absence from the hospital when ongoing compulsory in-patient treatment is still thought to be necessary.

Generally, but not exclusively, appropriate for shorter periods away from hospital.

Guardianship

Used to ensure that predominantly welfarebased needs are met away from hospital.
Supervised community treatment

To be used when it is not thought that the individual requires ongoing treatment in hospital, but the responsible clinician needs to be able to recall the individual to hospital if necessary.

Used to prevent repeated (particularly compulsory) admission to hospital.

(Department of Health 2008a)
For those detained under Part 3 of the Act and subject to a restriction order, leave may only be granted with the consent of the Secretary of State for Justice.

\section{Planning Section 17 leave}

When planning Section 17 leave, ongoing and not wholly resolved risks must be acknowledged and mitigated by appropriate care planning. The correct balance of risk management and therapeutic gain depend on effective communication between the treating team, patient and family. Conditions may be added to the leave to ensure effective management of risk and/or to maximise therapeutic gain. They will depend on individual circumstances and the reason for granting leave. Any conditions should be clear and reasoned.

\section{Ending Section 17 leave}

Effective planning should minimise the potential for difficulties arising during a period of leave. In order to revoke leave, the responsible clinician must be of the opinion that it is necessary to terminate

BOX 3 The professionals involved under the Mental Health Act 1983

Approved clinician A mental health practitioner (doctor, psychologist, social worker, nurse or occupational therapist) approved for the purposes of the Act by, or on behalf of, the Secretary of State in England (or the Welsh Ministers in Wales). Approved clinicians may be from a variety of clinical professions but must demonstrate specific competencies and undertake approved training.

Approved mental health professional A social worker or other professional (but not a doctor) approved by a local social services authority to perform a variety of functions under the Act. Prior to the 2007 amendments such functions were undertaken by the approved social worker (ASW)

Responsible clinician For detained patients and those subject to SCT, the responsible clinician is the approved clinician in overall charge of the patient's case. Responsible clinicians have various specific powers and duties under the Act in respect of their patients. Prior to the 2007 amendments these functions were generally undertaken by the responsible medical officer (RMO).

Second opinion appointed doctor An independent doctor called on to support a responsible clinician's decision regarding treatment under the Act. leave in the interests of the patient's health or safety, or for the protection of others. Notice of the revocation must be served in writing.

It is established that careful review is required before periods of leave. Similarly, there should be a review following leave to ensure that therapeutic benefits have been maximised and potential risks minimised.

\section{Limits of Section 17 leave}

Clinicians have sometimes used Section 17 leave of absence as a 'long leash' to allow the continued treatment of patients in the community with the power to recall to hospital if the clinical situation warranted it (Hewitt 2003). This approach represents something of a duplication of the authority within SCT. The amendments attenuate the powers of Section 17 by clearly differentiating between SCT and Section 17 leave. The Mental Health Act Code of Practice (Department of Health 2008a) provides guidance on use (Box 2) and the responsible clinician is required to consider SCT as an alternative whenever Section 17 leave exceeds 7 consecutive days.

\section{Guardianship}

The purpose of Section 7 provisions (guardianship) is to ensure that an individual receives appropriate care, largely of a welfare nature, outside of hospital if it cannot be provided voluntarily. The guardian (the local social service authority or the individual authorised by it) may decide where someone should live, require that the person attend for treatment or activity (although cannot force such attendance) and allow specific people to visit the individual's place of residence.

There is potential for uncertainty at the interface between the use of guardianship and the Mental Capacity Act 2005, in particular the 'deprivation of liberty safeguards'. This will be considered in detail in a future issue of Advances (Brindle 2010).

The only change to guardianship brought about by the 2007 amendments to the Mental Health Act is clarification that there is a power to convey a person to the specified residence. Prior to this there was widespread uncertainty about such authority and a resulting variation in practice.

\section{Supervised community treatment}

The introduction of SCT represented a major new direction for mental health legislation and has the potential to radically change the practice of professionals and the experiences of service users.

The purpose of SCT, as stated in the Code of Practice, is to provide an alternative to ongoing compulsory treatment in hospital and to prevent 
relapse and the harm associated with it. It provides a framework for care to be delivered in the community while allowing the responsible clinician to recall the individual promptly and forcibly to hospital if necessary.

\section{Criteria for SCT}

In keeping with the aim of preventing relapse in those who are particularly vulnerable, SCT can only be considered for individuals who are detained in hospital for treatment (i.e. Section 3 or unrestricted Part 3 detention). In addition, the following criteria apply:

- the person must have a mental disorder of a nature or degree which makes it necessary for them to receive medical treatment;

- such treatment must be necessary for their health or safety or for the protection of others;

- appropriate treatment needs to be available without the need for a return to hospital;

- it must be necessary for the responsible clinician to be able to recall the patient to hospital.

In determining this final point, the responsible clinician will need to consider the history of mental disorder and what the Mental Health Act Code of Practice refers to as 'any other relevant factors' (Department of Health 2008a). The responsible clinician should consider that the risks arising from the person's mental disorder are sufficiently serious to require the power of recall to hospital. These may include risks to the patient's well-being and social network as well as risks of neglect, vulnerability, suicide and harm to others. A comprehensive understanding of both nature and degree of the disorder will therefore be required.

If the power of recall is not required in order to provide effective and safe ongoing care, or appropriate treatment is not available, SCT will not be appropriate. Box 4 provides a summary of the criteria.

In addition to the above, in practice, the patient would need to agree to SCT and accept the conditions. This agreement cannot be seen as meaning the same as choosing SCT as their preferred framework for ongoing care. It is likely that patients will often be faced with deciding on the lesser of two evils - continued detention in hospital or SCT.

Issues such as the meaning within the Mental Health Act of mental disorder, medical treatment and appropriate treatment need to be considered in light of other amendments to the Act (for a detailed discussion in Advances of definitions and criteria of the Act see Branton 2010).

The decision as to whether to apply SCT or not therefore requires a thorough knowledge of the patient's presentation and history. It requires
BOX 4 Criteria for supervised community treatment
- The person must be detained under an unrestricted treatment order (e.g. Section 3)

- The mental disorder is of a nature or degree which makes it appropriate for the

- Such treatment is necessary for their health or safety or the protection of others

- Such treatment can be provided without return to hospital person to receive medical treatment
- The responsible clinician should be able to exercise the power of recall

- Appropriate medical treatment is available

- In addition, the responsible clinician must consider potential risks should the patient's condition deteriorate, the history of the disorder and any other relevant factors the agreement of both a responsible clinician and an approved mental health professional (Box 3). The two professionals are also required to agree at the outset on the conditions to be imposed by the CTO.

Given the need for someone to be detained in hospital for treatment before SCT can be applied, it is likely that in many services the responsible clinician applying SCT in hospital will be a different person from the responsible clinician when the person is in the community. There is no legal requirement for a 'community responsible clinician' to be involved in the decision to apply SCT, but it is clearly clinically necessary that they are closely involved in both the decision to use SCT and in discussions about which conditions should be applied. This situation could be mirrored when a patient is recalled to hospital where, once again, the responsible clinician could change. The need to allow multiprofessional discussion with involvement of the patient, family and carers as well as to clearly communicate treatment plans means that the care programme approach (CPA) should be central to the process.

\section{Conditions attached to SCT}

Considering and agreeing the conditions to be attached to SCT is an essential part of developing an appropriate care and treatment plan (Box 5). As well as the responsible clinician and approved mental health professional needing to agree on the conditions at the outset, it is important to involve the patient, other professionals, as well as family and carers in the process.

Two conditions are mandatory and apply in all cases. These are that the patient must allow examination by the responsible clinician in order to extend SCT (under Section 20A of the Mental Health Act) as necessary and also must allow examination by the second opinion appointed doctor (SOAD; Box 3) at the time necessary to authorise treatment. 
BOX 5 Conditions attached to supervised community treatment

The two mandatory conditions are:

- allow assessment by responsible clinician in order to extend SCT

- allow examination by SOAD in order to authorise treatment.

Additional conditions must be necessary to:

- provide medical treatment for the mental disorder, or

- prevent harm to patient's health or safety, or

- protect others

In addition, the patient and (initially) the approved mental health professional must agree to them.

Any other conditions must be clear, specific and reasoned. They must be necessary for at least one of the following purposes:

- to ensure the receipt of medical treatment for mental disorder

- to prevent risk of harm to the patient's health or safety

- to protect others.

Clinicians need not add any conditions beyond those that are mandatory. Any conditions attached should be considered and delivered as part of a CPA care plan.

In keeping with the purpose of SCT to reduce the damaging impact of mental disorder and the overarching principles of the Mental Health Act (Box 2), any conditions must restrict an individual's life as little as possible without defeating the purpose. Consideration should therefore be given to the consequences of applying the conditions. If a patient breaks a condition and this is ignored by the treating team, the authority of the order would appear to be undermined. It would not be good practice to have conditions in place if no action was taken when broken.

Once SCT is initiated, the responsible clinician may vary the attached non-mandatory conditions without reference to the approved mental health professional. However, it would normally be expected that such decisions would be undertaken with appropriate consultation and care planning.

\section{Recall to hospital}

The responsible clinician has sole authority to recall a patient on SCT and may do so without consultation. At times, because of the urgency, it may be necessary to act in this way. In most circumstances it is likely that recall is agreed following consultation with other professionals, the patient, family and carers. The power to recall is not an alternative to the responsible clinician considering other forms of care such as informal admission or use of services which provide alternatives to admission. Supervised community treatment should not be an obstacle to good clinical care or prevent access to the usual range of treatment options. Recall is a mechanism to ensure that appropriate treatment is given without the need for unnecessary deterioration in mental health.

The patient can only be recalled to a hospital, although in practice this does not require an identified bed. The purpose of the recall is to allow an assessment as to whether SCT can continue, including the appropriateness of voluntary admission or whether compulsory admission is necessary. In some cases recall may be solely to administer medication (see 'Medication for mental disorder in hospital' below). The patient may be held in the hospital (or transferred to another) for up to $72 \mathrm{~h}$ while awaiting completion of the assessment.

If the patient has refused examination by the SOAD (to authorise treatment) or the responsible clinician (to extend SCT) the patient should then be recalled to hospital for assessment. However, in other circumstances, there must be a perceived risk of harm to their health or safety or a concern for the protection of others and a requirement for treatment in hospital for mental disorder.

In practice, the process of recall to hospital may be less than straightforward. The responsible clinician must provide written notice to the patient outlining the reasons for recall. This written notice may be given by hand, hand-delivered to the last known address or posted. If given to the patient by hand, recall takes immediate effect. If handdelivered to the patient's last known address, recall takes effect from the day after it was delivered. If sent by first-class post, recall takes effect from the next working day after that. These details are important as the patient may be considered absent without leave (and an application for a warrant may be made under Section 135) if they do not comply with a recall notice.

The responsible clinician is responsible both for the delivery of the recall notice and conveyance to hospital. As is the case with detention from the community, the mode of conveyance - ambulance or police - will depend on the circumstances.

Once in hospital, the clinical team will be able to give treatment as authorised. Parallel to this, they must assess whether continued detention for assessment and/or treatment in hospital is necessary. The responsible clinician in agreement with an approved mental health professional may revoke the CTO if criteria are met. 
Given that patients subject to SCT are likely to be those for whom relapse represents a time of increased risk, it is evident that there should be clear and effective communication and information sharing between the responsible clinician and those undertaking the assessment following recall. In a modern health service, it may be that the responsible clinician varies depending on where the patient is receiving treatment at the time. There must therefore be a robust framework for decision-making in these acute situations. This should include both advanced planning and communication of treatment and concerns at the time of recall. Once again, CPA provides a framework for this.

Once recalled to hospital the patient is considered as liable to be detained for the purposes of administering medical treatment.

\section{Revocation}

Following recall to hospital the patient is assessed and may receive treatment. The choice is then to either continue with SCT (which may include voluntary admission) or to undertake an assessment for revocation.

The criteria for revocation are similar to those for detention under Section 3. Both the responsible clinician and approved mental health professional have to agree to revocation. Revocation ends SCT and the patient is once again detained under the section from which SCT was initiated. There is an automatic referral to a mental health review tribunal and a new period of detention for the purposes of renewal is begun. As will be seen below, it is not considered as a new period of detention with regard to consent to treatment.

\section{Renewal, discharge and safeguards}

Community treatment orders are renewed by the responsible clinician following consultation with at least one other professional involved and with the agreement of the approved mental health professional. Periods of renewal are 6 months in the first instance and then every 12 months thereafter.

As with Section 3, patients may be discharged from SCT by the responsible clinician (and must be if criteria are no longer met), by hospital managers or by a mental health review tribunal. The nearest relative may also apply for discharge. It is noteworthy that patients placed on SCT now have the right to an independent mental health advocate.

Given the power of recall, it should not be necessary to make a fresh application for detention. However, in practice (e.g. if the professionals involved are unaware of a CTO) it may be the case that a patient is detained to hospital once again under the Mental Health Act. An application for detention under Section 2 does not affect the SCT. However, if detained under Section 3, the SCT would end (unless the SCT was initiated from an unrestricted Part 3 treatment order). Similarly, if the patient was received into guardianship (Section 7) then the SCT would end.

\section{Treatment under SCT}

For the purposes of treatment, SCT runs in two phases. In the community, authority to treat the patient is regulated by Part $4 \mathrm{~A}$ of the Act. In hospital, where the patient may be recalled and detained following revocation, the authority comes (generally) from Part 4.

\section{Medication for mental disorder in the community}

For treatment in hospital under Part 4, a SOAD is not required if the patient has capacity and consents to treatment. For patients in the community, a SOAD is required to authorise all medication for mental disorder whether or not the patient agrees. Authorisation from a SOAD is required 3 months after medication was first given under detention in hospital prior to SCT or 1 month into the period of SCT, whichever is later. Thus, a patient detained under Section 3, given medication for mental disorder on 1 January, and discharged from hospital on to SCT on 15 March will require authorisation of treatment on 15 April (as 15 April is later than 1 April).

Apart from the initial period of SCT before a $\mathrm{SOAD}$ is required, medication for mental disorder can only be given to a person who has capacity to consent if they do indeed consent to the treatment and if that treatment is authorised by the SOAD. If there is no authorisation by a SOAD, in an emergency medication may be given with capacitous consent but not in the face of capacitous refusal.

If the patient lacks capacity to consent to treatment, any substitute decisions (e.g. advance refusal or authorised lasting power of attorney) must be respected. If there are no substitute decisions, medication may be given under the direction of the approved clinician as long as force is not required to overcome an objection. In an emergency, treatment may be given without the approved clinician's direction and force may be used if it is in order to prevent harm to the patient and is proportionate. In these circumstances, it may also be given contrary to a substitute decision.

When making a request for a SOAD, the responsible clinician must make clear not only which medication will be used to treat the mental disorder, but also the circumstances (including recall) under which they are requesting authorisation for treatment. 
In practice, these safeguards will be significant. Despite the patient's agreement, it may not be possible to make changes to medication if it falls outside that authorised by the SOAD. For example, pharmacological treatment of an emergent depressive episode in someone being treated for psychosis will require additional authorisation.

In the community, SCT does not provide a platform for treating people who could not otherwise be treated.

\section{Medication for mental disorder in hospital}

If admitted informally, Part 4A of the Mental Health Act will continue to apply to treatment.

On recall to hospital, the patient is again, for the purposes of treatment, subject to detention.

If, on recall or revocation, medication for mental disorder is to be given under Part 4 of the Act, it must be authorised by a SOAD (form CTO3) or have the capacitous consent of the patient and the authority of the approved clinician (form CTO2). An exception to this is where a patient is recalled to hospital before the SOAD is required to authorise treatment in the community (i.e. before the 3-month rule or before 1 month of SCT, whichever is later). In this case, treatment may be given without the need for any (new) certificate. For the purpose of Section 58, recall to hospital should not be considered as a new episode of detention.

In addition, on recall, the SOAD may specifically authorise medication to be given under Part 4A. It is therefore possible that on recall to hospital both Part 4 and Part 4A may apply to treatment.

This authority to treat under Part $4 \mathrm{~A}$ on recall is a key aspect of SCT. It allows the responsible clinician to bring someone back to hospital, give medication and return them to the community within a short time frame. In order to authorise such treatment, however, the SOAD needs to be confident that this can be done safely. The responsible clinician requires an in-depth understanding of the patient's presentation when unwell, the course of their illness and likely circumstances of recall.

On recall or revocation, SCT allows for medication authorised by the SOAD for treatment in the community under Part $4 \mathrm{~A}$ to be continued if the approved clinician in charge of medication considers that to stop it would cause serious suffering. It can only continue, however, while awaiting compliance with Part 4 provisions.

Table 1 summarises the authority for treatment of an individual placed on SCT and Fig. 1 outlines the SCT pathway.

\section{Impact of SCT}

The introduction of SCT was probably the most controversial of the 2007 amendments and has been central to the government's reform of mental health legislation. Its stated purpose is to help those who have repeated episodes of illness and admissions to hospital to maintain good mental health and reduce the disabling effect of repeated relapse. This would also have the effect of reducing risks associated with such relapse.

However, in contrast to many psychosocial interventions that share the same goal, SCT is not so obviously collaborative. As SCT is a route out of compulsory admission, the patient's initial agreement to a CTO could be seen as coercive. If this is the starting point of a community treatment plan, there is concern that the threat of recall will dissuade patients from disclosing emerging symptoms. This raises the very real question of how effectively engagement-based approaches that currently dominate care plans can work alongside an approach that relies on coercion and compulsion.

Patients' views and experiences of SCT are important in determining its use and effectiveness. Interestingly, a New Zealand study (Gibbs 2005) found patients subject to CTOs to view them broadly

TABLE 1 Summary of authority to give medication for mental disorder

\begin{tabular}{|c|c|c|c|c|c|}
\hline & \multirow{2}{*}{$\begin{array}{c}\text { Mental Health Act } \\
\text { Section } 3 \\
\text { (or equivalent) }\end{array}$} & \multicolumn{2}{|c|}{$\begin{array}{l}\text { Supervised community treatment } \\
\text { in the community }\end{array}$} & \multirow{2}{*}{$\begin{array}{c}\text { Supervised } \\
\text { community treatment } \\
\text { on recall }\end{array}$} & \multirow{2}{*}{$\begin{array}{c}\text { Supervised } \\
\text { community treatment } \\
\text { on revocation }\end{array}$} \\
\hline & & Capacitous ${ }^{a}$ & Incapacitous ${ }^{a}$ & & \\
\hline $\begin{array}{l}\text { Routine } \\
\text { medication for } \\
\text { mental disorder }\end{array}$ & $\begin{array}{l}\text { Part } 4 \text { - can be given up } \\
\text { to } 3 \text { months after first } \\
\text { detention medication. } \\
\text { Thereafter requires } \\
\text { SOAD or capacitous } \\
\text { consent. }\end{array}$ & $\begin{array}{l}\text { Part } 4 A \text { - can be given } \\
\text { for up to } 3 \text { months } \\
\text { after initial detention } \\
\text { treatment or } 1 \text { month } \\
\text { into SCT, whichever is } \\
\text { later. Thereafter requires } \\
\text { SOAD. }\end{array}$ & $\begin{array}{l}\text { Part } 4 \mathrm{~A}-\text { not } \\
\text { contrary to substitute } \\
\text { decision. Under } \\
\text { direction of approved } \\
\text { clinician. Cannot use } \\
\text { force. Otherwise as } \\
\text { for capacitous. }\end{array}$ & $\begin{array}{l}\text { Part } 4 \text { - as for Section } 3 . \\
\text { If SCT }<1 \text { month, this is } \\
\text { not included in 3-month } \\
\text { calculation. } \\
\text { Part } 4 A \text { - if certified by } \\
\text { SOAD. }\end{array}$ & $\begin{array}{l}\text { Part } 4 \text { - certificate } \\
\text { required if }<3 \text { months from } \\
\text { first medication under } \\
\text { detention. New certificate } \\
\text { unless SCT }<1 \text { month. }\end{array}$ \\
\hline $\begin{array}{l}\text { Emergency } \\
\text { medication for } \\
\text { mental disorder }\end{array}$ & Part 4 - Section 62 & $\begin{array}{l}\text { Part } 4 A-\text { Section } 64 B / C \\
\text { only if consenting }\end{array}$ & $\begin{array}{l}\text { Part } 4 A-\text { Section } \\
64 G \text { if force } \\
\text { proportionate to risk } \\
\text { of harm to self. }\end{array}$ & $\begin{array}{l}\text { Part } 4 A \text { - if authorised } \\
\text { by SOAD } \\
\text { Part } 4 \text { - Section } 62\end{array}$ & Part 4 - Section 62 \\
\hline
\end{tabular}

a. With regard to proposed medication. 


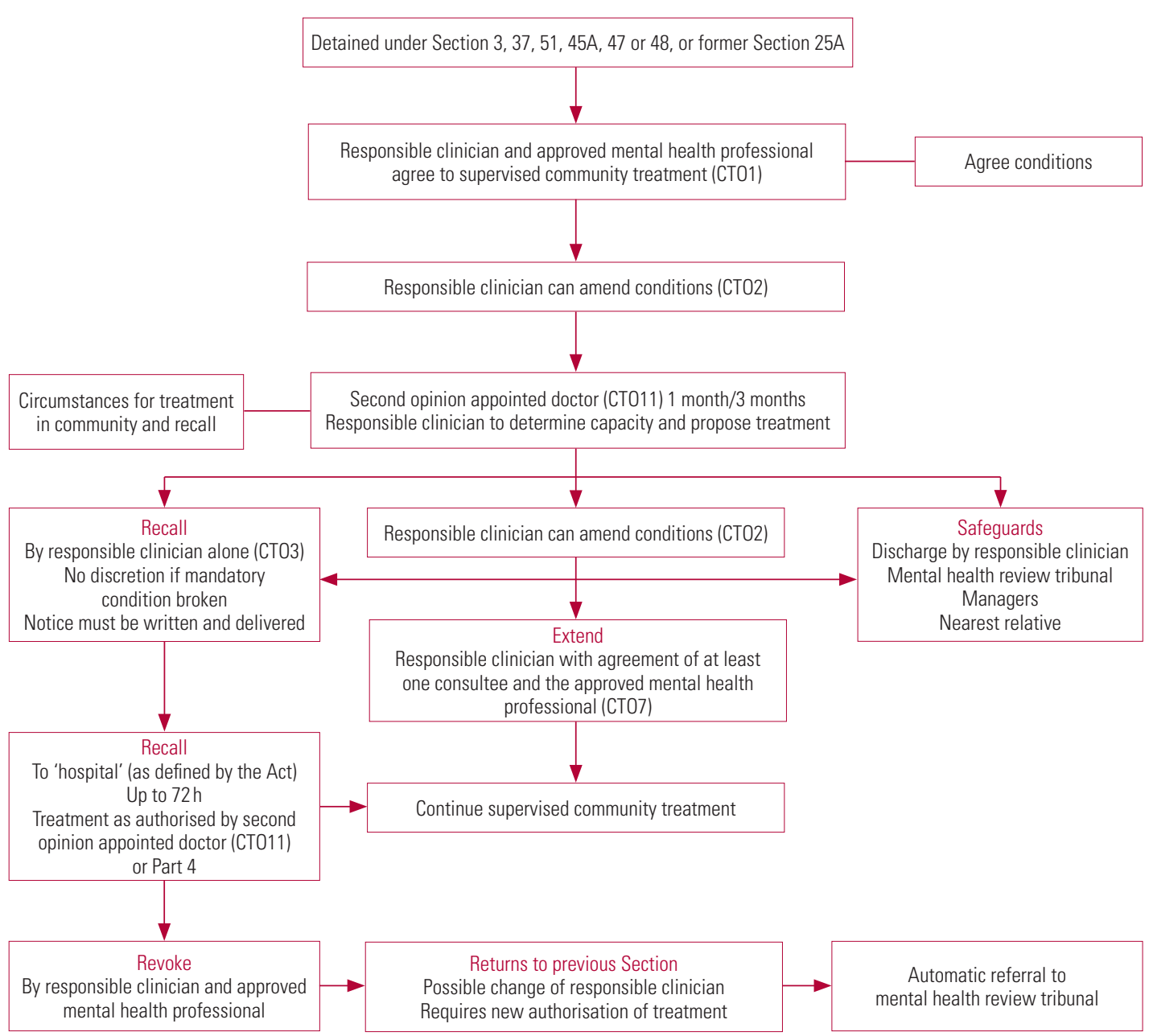

Supervised community treatment pathway. СT02, СT03, etc. refer to the forms that must be completed at the corresponding stages (Department of Health 2008b: Appendix B).

favourably, describing improved mental health, sense of security and access to services. Perhaps predictably, however, they also described a sense of loss of control, of increased stigma and of coercion to adhere to medication. These views affected their relationships with health professionals.

Beyond the ethical there will also be clinical dilemmas for clinicians. Will the apparent ease with which patients showing early signs of risk can be recalled to hospital make SCT more or less attractive to clinicians? Will clinicians feel obliged to recommend SCT simply to be seen to have done all they can to reduce the risks associated with recurrent and severe mental illness? Having decided on SCT, will clinicians feel pressure to impose restrictive conditions in an attempt to have greater control over 'risky' patients?

Deciding on what conditions to apply will not be straightforward. They must fulfil the requirements listed in Box 4 but must also be clinically useful and enforceable. It may be desirable and clinically relevant to have a condition requiring someone to take oral medication on a daily basis but is it real- istic? What about limiting the intake of alcohol? Given the need to promote a full and independent life can (or perhaps should) clinicians ever know whether such conditions are complied with?

After little more than 18 months of experience in England and Wales it is hard to draw firm conclusions about how CTOs will be used and will affect wider clinical care. It is, however, worth considering the experience of the model elsewhere in the world. Comparisons with international experience are limited by differences in statutory frameworks. A Cochrane review (Kisely 2005) of trials conducted in the USA did not find evidence to support the hope that SCT would reduce, among other things, readmission or would improve quality of life. A review of international experience of CTOs (Churchill 2007) illustrated the difficulty in drawing clear conclusions on current evidence and similarly could not support the view that such orders would reduce relapse rates or improve adherence to treatment.

A major ingredient of SCT is the ability to give treatment, if necessary in the face of refusal, on 
MCO answers

$1 d \quad 2 c \quad 3$ e 4 e $5 d$

‡See also Lyons D (2010) Different laws, same principles: mental health legislation across the UK. Advances in Psychiatric Treatment 16: 158-60. Ed. recall to hospital. The demands on SOADs will be significant in terms of both the time required to undertake the assessment and the extensive knowledge needed of the course and severity of the patient's illness. The requirement that the SOAD, and thus the service, has a thorough understanding of the patient and the disorder would suggest that SCT will be most used for patients who have experienced frequent relapses, often linked to incomplete adherence to medication. Early data from the use of community CTOs in Scotland suggests that this is the case (Lawton-Smith 2006). ${ }^{\ddagger}$

Despite uncertainty elsewhere in the world regarding effectiveness in reducing relapse and promoting recovery, clinicians in England and Wales have embraced SCT. The Department of Health (2006: p. 55) estimated that $2 \%$ of potentially eligible patients (about 200) would become subject to SCT in the first year, rising to $10 \%$ (about 2250) after 5 years. The initial projection was far exceeded after only 5 months, with over 2100 CTOs being completed by the end of March 2009 (NHS Information Centre for Health and Social Care 2009).

It must be assumed that clinicians are making individual decisions about SCT in line with the guiding principles set out in the Codes of Practice for the Mental Health Act (Department of Health 2008a: pp. 5-6; Welsh Assembly Government 2008: pp. 5-9) and, as well as minimising risk, are seeking to promote well-being and recovery. It would be hoped that in time the decision can also be informed by robust and relevant information regarding the effects and effectiveness of SCT.

\section{References}

Branton T, Brookes G (2010) Definitions and criteria: the 2007 amendments to the Mental Health Act 1983. Advances in Psychiatric Treatment 16: 161-7

Brindle N, Branton T (2010) Interface between the Mental Health Act 1983 and Mental Capacity Act: the deprivation of liberty safeguards. Advances in Psychiatric Treatment in press.

Churchill R, Owen G, Singh S, et al (2007) International Experiences of Using Community Treatment Orders. Department of Health.

Department of Health (2006) Mental Health Bill: Regulatory Impact Assessment. TSO (The Stationery Office)

Department of Health (2008a) Code of Practice. Mental Health Act 1983. TSO (The Stationery Office).

Department of Health, National Institute for Mental Health in England (2008b) Supervised Community Treatment: A Guide for Practitioners. NIMHE.

Gibbs A, Dawson J, Ansley C, et al (2005) How patients in New Zealand view community treatment orders. Journal of Mental Health 14: 35768

Hewitt D (2003) There is no magic in a bed: the renewal of detention during a period of leave. Journal of Mental Health Law August: 87-101.

Kisely SR, Campbell LA, Preston NJ (2005) Compulsory community and involuntary outpatient treatment for people with severe mental disorders. Cochrane Database of Systematic Reviews issue 3: CD004408.

Lawton-Smith (2006) Community-based Compulsory Treatment Orders in Scotland. The Early Evidence. King's Fund.

Mental Health Alliance (2006) Mental Health Bill still not fit for the twenty-first century, says Alliance. Press release, 17 November (http:// www.mentalhealthalliance.org.uk/news/prbillpublished.html).

NHS Information Centre for Health and Social Care (2009) In-patients Formally Detained in Hospitals under the Mental Health Act 1983 and Patients Subject to Supervised Community Treatment: 1998-99 to 200809. The Health and Social Care Information Centre (http://www.ic.nhs. uk/statistics-and-data-collections/mental-health/mental-health-act/ in-patients-formally-detained-in-hospitals-under-the-mental-health-act1983-and-patients-subjects-to-supervised-community-treatment:-199899-to-2008-09).

Welsh Assembly Government (2008) Mental Health Act 1983: Code of Practice for Wales. TSO (The Stationery Office)

\section{$\mathrm{MCOs}$}

Select the single best option for each question stem

\section{On recall:}

a the patient may be held under Section 5.2 if further time is required for assessment after the $72 \mathrm{~h}$ has passed

b a referral to a mental health review tribunal must be made

c medication for mental disorder may be given against the patient's wishes if authorised by an approved clinician

$\mathrm{d}$ the patient may be transferred to another hospital while remaining on recall

e recall may be to a police station if this is considered a 'place of safety'.

2 For someone originally detained under Section 3, SCT is automatically ended by: a detention under Section 136

b application for discharge by nearest relative c admission under Section 3 d admission under Section 2

e informal admission to hospital.

3 A SOAD is always required to authorise:

a routine medication for mental disorder for a patient admitted on a voluntary basis 6 months into SCT

b nursing care to be delivered to a patient in a nursing home and subject to SCT

c emergency treatment for mental disorder (according to Section 62) to be given to someone on SCT who does not have capacity to consent

d medication for mental disorder in a capacitous patient 1 month into SCT

e routine medication for mental disorder in a capacitous patient requesting treatment 4 months into SCT.

4 A patient on SCT:

a cannot be admitted on a voluntary basis b must be recalled to hospital if their mental health deteriorates significantly

c has the right to an independent mental health advocate only when recalled to hospital or on revocation

d can collect free prescriptions for medication

e if discharged from SCT by a mental health review tribunal, is also discharged from the original detention (e.g. Section 3).

\section{Section 17 leave of absence:}

a can be authorised by the responsible clinician or nominated deputy

b cannot exceed 7 consecutive days

c cannot be extended without the need to return to hospital

d can be granted to a patient subject to restricted Part 3 detention only with the permission of the Secretary of State for Justice

e must be preceded by a care programme meeting. 